\title{
Assessment of Respiratory Exposure Risk Due to Continuous Positive Airway Pressure Ventilation in Obstructive Sleep Apnea
}

\author{
DOINA ADINA TODEA ${ }^{1}$, ANCA DANA BUZOIANU², STEFAN CRISTIAN VESA², SORIN CLAUDIU MAN ${ }^{3 *}$, ANDREEA COMAN² \\ ${ }^{1}$ I uliu Hatieganu University of Medicine and Pharmacy, Department of Pneumology, 8 Victor Babes Str., 400012, Cluj Napoca, \\ Romania \\ ${ }^{2}$ Iuliu Hatieganu University of Medicine and Pharmacy, Department of Pharmacology, Toxicology and Clinical Pharmacology, , \\ 8 Victor Babes Str., 400012, Cluj Napoca, Romania \\ ${ }^{3}$ Iuliu Hatieganu University of Medicine and Pharmacy, Mother and Child Department, , 8 Victor Babes Str., 400012, Cluj Napoca, \\ Romania
}

\begin{abstract}
Our study aimed to identify inorganic elements and bacterial load on the inner surface of the CPAP masks and tubing using scanning electron microscopy (SEM), and energy-dispersive X-ray spectroscopy (EDX) and microbiological surface analysis. By SEM were identified structures similar to Staphylococcus and Candida types. When completed by EDX were identified $\mathrm{Cl}, \mathrm{K}, \mathrm{Ca}, \mathrm{O}, \mathrm{Ti}, \mathrm{Na}, \mathrm{Mg}, \mathrm{Al}, \mathrm{Si}, \mathrm{S}, \mathrm{Cl}$. Microbiological analysis identified Staphylococcus epidermidis (5000 CFU/mL), Staphylococcus hominis (8600 CFU/mL), and Staphylococcus haemolyticus (6500 CFU/mL). The presence of microbiological and inorganic structures raises concerns on the risk of their inhalation into the airways.
\end{abstract}

Keywords: electronic microscopy, microbiological surface analysis, microbial, inorganic

With a prevalence of 2-4\% among the adult population, obstructive sleep apnea syndrome (OSA) increasingly attracts the attention of health care providers [1]. The signs, symptoms and consequences of OSA have increased the interest in its diagnosis and early initiation of nocturnal continuous positive airway pressure (CPAP) therapy [1-3] . Compliance with CPAP therapy depends on the type of mask used and the frequency and severity of side effects such as nasal symptoms, mask leaks, claustrophobia, skin lesions, and conjunctivitis [4]. Thus, choosing an adequate mask as well as maintaining a low microbiological and inorganic risk associated with its use plays a key role in increasing the success of CPAP therapy.

The masks used for the therapy of OSA are of 3 types: nasal, oronasal and facial. Their structure includes the following significant components: polycarbonate which composes the mask structure, silicone making up the structure of the cushion that is sealed to the patient's face, and urethane gel enclosed in a polypropylene bag which has a role in supporting the mask on the forehead [5]. The tubing attached to the CPAP mask has a tubular structure, with folds, a 19-mm diameter and $2 \mathrm{~m}$ length, and is made of latex [6]. The inner surface of the masks has a tortuous structure and many cleavage points; the risk of bacterial colonization at this level is extremely high. Because the CPAP ventilation system is a closed one, an increased microbial load of the mask allows the spread of bacterial colonies in the lower respiratory tract, and a direct contact of bacterial colonies with the anatomical structures of the upper airways.

Continuous positive airway pressure (CPAP) exposes the respiratory tract to the inhalation of inorganic particles of various sizes or different microbial structures (bacterial or fungal), which can pose a risk for subsequent respiratory diseases. Currently, there are robust studies that address the bilateral organic and inorganic risk of CPAP ventilation for the therapy of sleep apnea [7]. Some publications on the bacterial colonization of CPAP circuits for non-invasive ventilation (NIV) at home and their connection with respiratory tract infections are available $[8,9]$.
The aim of this study was to identify inorganic elements and organic structures on the inner surface of the masks and tubing attached to nocturnal CPAP ventilation machines for the therapy of OSA, by complex and innovative bidirectional methods. We previously presented our findings on inorganic and organic elements identified by scanning electron microscopy (SEM) [7]. Here we are analyzing the morphology of organic elements and the confirmation by microbiological analysis, as well as the bacterial load on the inner surface of the CPAP masks and tubing.

\section{Experimental part}

This analysis comprises two types of research:

- Identification of the presence of organic elements using SEM and energy-dispersive X-ray spectroscopy (EDX).

- Identification of types of microorganisms presents and of bacterial load using microbiological surface analysis.

\section{Collection of samples}

As previously described [7], between January 2015 April 2015 samples from the most tortuous areas of 44 masks and 44 tubes used at home with CPAP machines by patients diagnosed with OSAS and followed up by the Sleep Laboratory of the Iuliu-Hatieganu University of Medicine and Pharmacy Cluj-Napoca were collected at the time of presentation for periodic evaluation. Samples were collected only from patients who used the CPAP machine for at least 4 weeks before study inclusion and only for those patients with no humidifier attached to the CPAP machine. 1 sealed mask and 1 sealed tube were used as controls. All masks were nasal, the ComfortClassic, EasyLife and Wisp types from Philips Respironics.

Sample collection for SEM and EDX analysis was done using $5 \mathrm{~mm} \times 2.5 \mathrm{~mm}$ double-sided adhesive carbon tapes, with a disc diameter of $5 \mathrm{~mm}$. Sample collection for microbiological analysiswas done by brushing mask and tubing surface areas with peptone water-infiltrated sticks.

The study protocol was approved by the luliu Hatieganu University of Medicine and Pharmacy ethics committee.

* email: claudiu.man@umfcluj.ro; Phone: (+40)722 280947 
Informed consent of patients who used these CPAP devices at home was obtained prior to sample collection.

\section{Scanning electron microscopy and energy-dispersive X-ray} spectroscopy analysis

The identification of the presence of inorganic and organic elements was done by SEM and EDX analysis performed in the Electron Microscopy Laboratory at the Department of Materials Science and Engineering of the Technical University Cluj-Napoca, Romania. SEM was performed using a SM-5600 LV (JEOL) scanning electron microscope (SEM) with an EDS spectrometer (Oxford Instruments). The protocol used was previously described by Coman et al [7].

\section{Microbiological analysis}

The samples for microbiological surface examination were stored for approximately 20 minutes after collection and then transported to the laboratory for immediate processing. The culture medium used was peptone water due to non-selective enrichment of bacteria from food or other studied material. Peptone water was composed of $(\mathrm{g} / \mathrm{L})$ : peptone 10.0; sodium chloride 5.0; disodium phosphate hydrated with 12 water molecules 9.0; monopotassium phosphate 1.5. $\mathrm{pH} 7.2 \pm 0.2$ at $25^{\circ} \mathrm{C}$, and for preparation, it is autoclaved at $121^{\circ} \mathrm{C}$ for 15 minutes [10]. The cultures were read within 72 hours after samples collection.

\section{Statistical analysis}

Statistical analysis was performed using MedCalc Statistical Software version 16.8 (MedCalc Software bvba, Ostend, Belgium; https://www.medcalc.org; 2016).
Quantitative variables were tested for the normality of distribution with the Kolmogorov-Smirnov test. Quantitative variables were described using mean and standard deviation or median [the 25th-75th percentiles], according to their distribution. The analysis of the differences of quantitative variables between two groups was performed using Student t test or Mann-Whitney test, and the correlation was assessed by determining Spearman's rho correlation coefficient. The concordance between organic elements identified on tubes and masks was assessed by Cohen's kappa test. A p value $<0.05$ was considered statistically significant.

\section{Results and discussions}

Scanning electron microscopy and energy - dispersive $X$-ray spectroscopy analysis

At a magnification of $200 x$ to $10,000 x$, images obtained by SEM analysis of collected samples showed several inhomogeneous and homogeneous elements of variable sizes $(100-1 \mu \mathrm{m})$. The structures identified could represent microbiological structures, residues of living organisms or conglomerates of metallic or non-metallic chemical elements. Figure 1 shows disintegrated structures of various shapes surrounded by multiple microstructures (1000x magnification), representing potential residues of previously living microbiological structures.

Images in figure $2(a-d)$ present single structures with rounded edges, some oval, others cylindrical, possibly microbiological structures, on a clear background.

Figure 3 (a) shows multiple curved linear structures on a background with compact cubic structures. Following SEM and EDX (fig. 3 (b)) of the sample collected from the mask, the following chemical elements were identified at various titers: $\mathrm{Cl}, \mathrm{K}, \mathrm{Ca}, \mathrm{O}, \mathrm{Ti}, \mathrm{Na}, \mathrm{Mg}, \mathrm{Al}, \mathrm{Si}, \mathrm{S}, \mathrm{Cl}$.
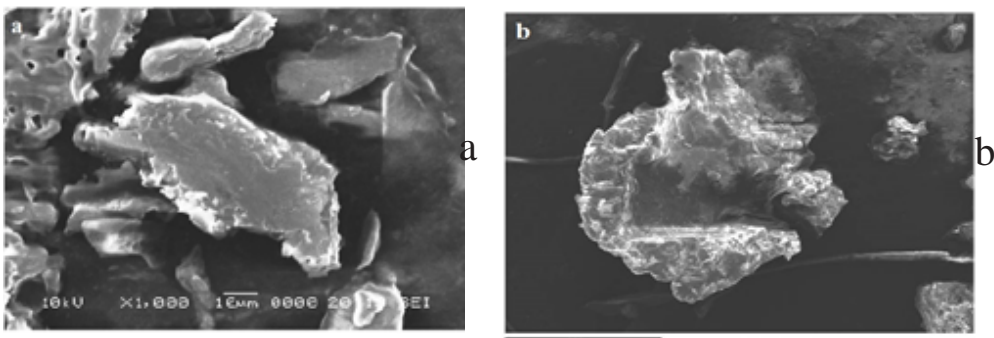

Fig. 1. Scanning electron microscopy micrographs of sample S07a ( $a$ and b), collected from the mask: ( $a$ ) structures of various rounded shapes; (b) - residual bosselated structure (bar scale between $10-200 \mu \mathrm{m})$
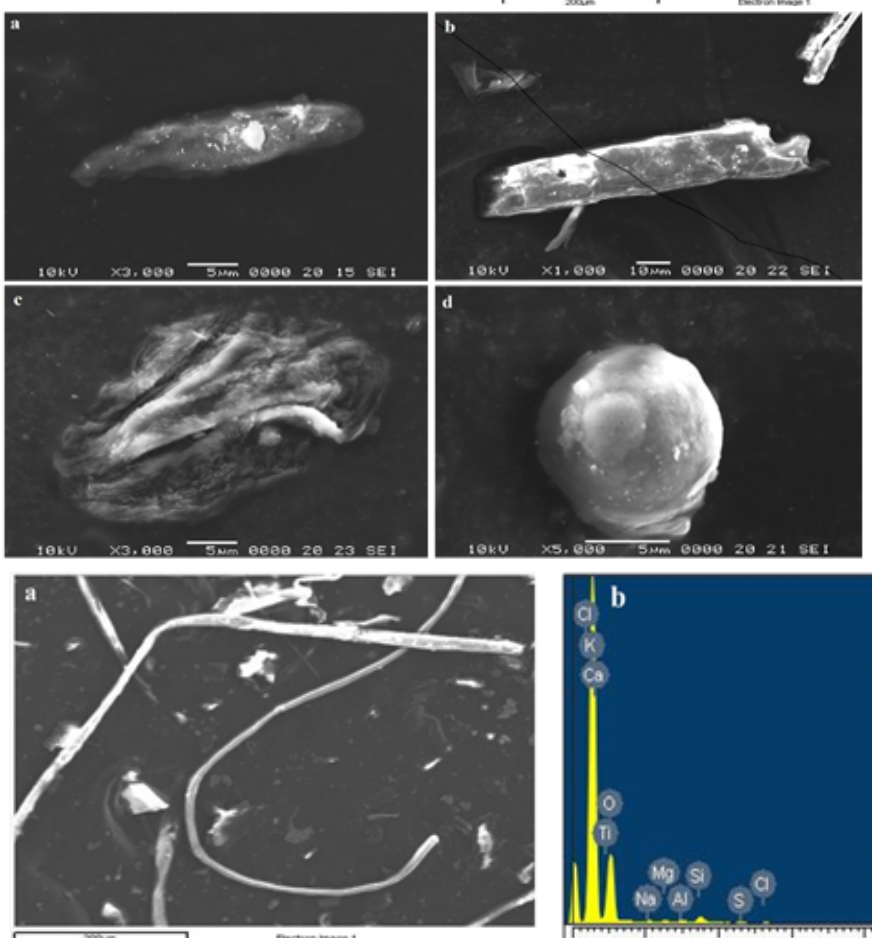

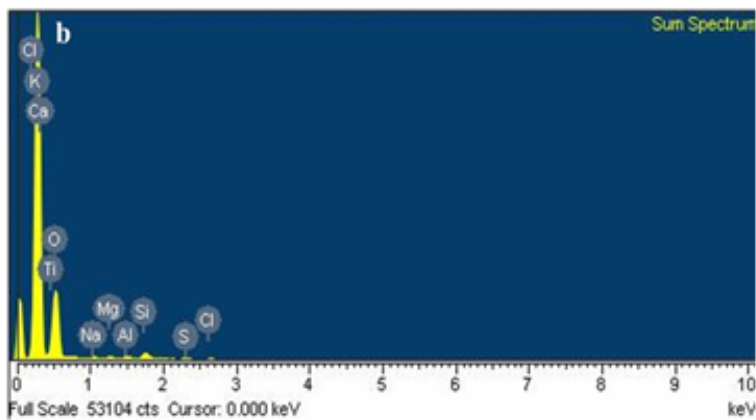

Fig. 3. SEM micrographs of sample S017a (a) and elemental distribution of the same sample S017a (b), collected from the mask:

a) multiple curved linear cylindrical, skeletal structures; b) SEM and EDX with the detection of many metallic and non-metallic chemical elements 
The image in figure 4 at a magnification of 10,000x show multiple conglomerated microbiological structures, of variable sizes and shapes, oval, bosselated, some with a size $<1 \mu \mathrm{m}$.

Figure $5(a$ and $b)$ shows at a magnification of $5,000 x$ and 10,000x, smooth larger structures on which adhere smooth round agglutinated elements. These are present on a background with unevenly distributed irregular structures of variousshapes, which maintain a pattern.

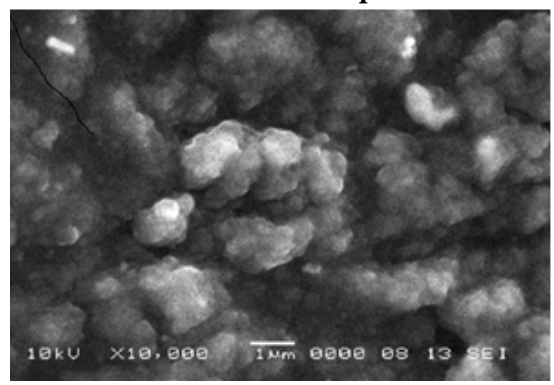

Fig. 4. SEM micrographs of sample S24a, collected from the mask: many structures of various shapes, rounded, bosselated; (bar scale $1 \mu \mathrm{m}$ )
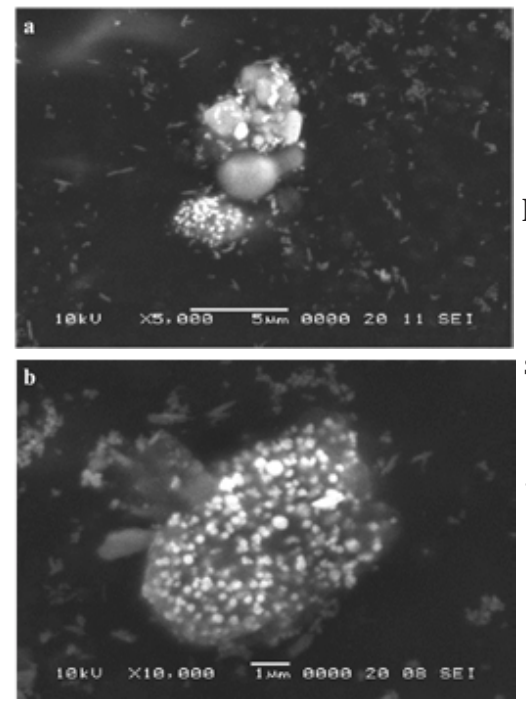

Fig. 5. SEM micrographs of sample S015a (a) and (b), collected from the mask: a) compact rounded structures to which round microbiological elements adhere (magnification $5,000 \mathrm{x}$ ) b) single compact structure to which many round microbiological elements adhere (magnification $10,000 \mathrm{x}$ ) (bar scale between 1-5 um)

Microbiological analysis

As previously stated 88 samples were collected from masks and tubes of 44 patients. Additionally, we collected 2 samples, 1 from an unused sealed mask and 1 from an unused sealed tube, as controls. These 2 samples had no bacterial colonies and were not included in the statistical analysis. Of the 88 samples collected from used masks and tubes, 12 had no bacterial colonies. The remaining ones had bacterial or fungal load in various CFU/ml concentrations, such as Staphylococcus (S.) epidermidis (5000 CFU/mL), S. hominis (8600 CFU/mL), and S. haemolyticus (6500 CFU/mL). Micrococcus luteus, Sphingomonas paucimobilis, S. cohnii spp. urealyticus, Kocuria kristinae, Candida krusei, Candida parapsilosis were also identified but with a lower load.

$S$. epidermidis was the most frequently identified microorganism in the samples collected from masks (18 of the 44 patients, $40.9 \%$ ). Patients in whose masks were identified $S$. epidermidis had been using the mask for $9.61 \pm 5.6$ months; those without $S$. epidermidis had been using the mask for $7.77 \pm 5.6$ months ( $p$ for the difference between groups $=0.2$ ). $S$. hominis was second most frequently identified microorganism, being detected on the samples collected from the masks of 13 patients (29.5\%). Patients with $S$. hominis had been using the mask for $10.31 \pm 6.8$ months before the sample collection. Patients without $S$. hominis had been using the mask for $7.77 \pm 4.9$ months before sample collection (for the difference between groups $=0.1$ ).

S. hominis was the most frequently microorganism identified on the tubes (in 12 patients of the 44 patients;
27.3\%). Patients in whose tubes were identified S. hominis had been using the tubes for longer time periods (11.67 \pm 7.4 months) compared to those without S. hominis ( $7.34 \pm 4.3$ months, $p=0.02$ ). In tubes from 4 patients was identified Sphingomonas paucimobilis. The time of use of tubing was significantly longer in patients with Sphingomonas paucimobilis (13.75 \pm 7.5 months) compared to those without Sphingomonas paucimobilis ( $8.00 \pm 5.2$ months, $p=0.05$ ).

A statistically significant positive correlation was found between the duration of use of the device (months) and the microbial load on the mask (CFU/mL; $r=0.562$; $p<0.001)$. No correlation was determined between the duration of use of the device and microbial load on the tubing $(r=0.172 ; p=0.2)$.

In order to assess whether the microorganisms present on the mask also occurred on the tubing, we used agreement analysis. Overall, there was a smaller probability for colonies to be present in both masks and tubes $(k=0.360 ; p=0.002)$. Regarding S. epidermidis, the masktubing agreement was moderate $(k=0.604 ; p<0.001)$. For $S$. haemolyticus, we determined a better tubing-mask agreement $(k=0.638 ; p<0.001)$ and for Staphylococcus hominis, agreement was high $(k=0.832 ; p<0.001)$.

For microorganisms present on both the mask and tubing, we calculated whether there was a statistically significant difference in bacterial load of the same bacterium on the 2 locations. The bacterial load was statistically significant higher on tubes than on the mask for S. epidermidis and S. hominis. No statistically significant difference was observed for $S$. haemolyticus. For $S$. epidermidis we determined a median bacterial load on the tubes of 2200 (1500; 3500) M/CFU/mL and on the mask of $900(700 ; 1000) \mathrm{T} / \mathrm{CFU} / \mathrm{mL}(\mathrm{p}=0.003)$. For $S$. hominis we determined on the tubing a median of $1500(800 ; 6000)$ $\mathrm{M} / \mathrm{CFU} / \mathrm{mL}$ and on the mask a median of $400(100 ; 900) \mathrm{T} /$ $\mathrm{CFU} / \mathrm{mL}(p=0.005)$. For $S$. haemolyticus we determined on the tubing a median of $800(525 ; 2475) \mathrm{M} / \mathrm{CFU} / \mathrm{mL}$, and on the mask a median of $600(275 ; 3200)$ T/CFU/mL $(p=0.3)$.

SEM is a technique that allows observing the morphology of bacteria adherent to the surface of a material, the morphology of the material's surface, as well as the interaction between the two. Environmental SEM and low vacuum SEM techniques do not require carbon or metal coating; in this way, the surface and adherent bacteria are protected from deterioration. The SEM technique used in this research required no amplification, thus samples were analyzed without the high suspicion of deterioration. However, SEM has several limitations, including the impossibility to differentiate between a viable and a dead structure. The images in our research suggest aspects of multiple colonies, single structures of variable sizes between 20-1 im, as well as some possibly dead residual skeletal structures of previously living microorganisms [11].

SEM, complemented by EDX, provides valuable qualitative and quantitative chemical information [12], but it also has biological applicability. It can evaluate bones, feathers, dry insects, even living cells and tissues, with previous preparation and fixation with fixing agents such as formaldehyde or glutaraldehyde $[13,14]$ or cryofixation [13]. As patients used the CPAP machines for long time periods we could not estimate the viability of microorganisms and thus we did not fix the samples, but we attempted to develop accurate inorganic and organic maps of the surface of masks and tubes used for CPAP.

Because were partly represented by thin microbiological elements that remain on the wafers, the organic and inorganic elements identified by SEM on the carbon tape 
were homogeneously distributed. The analyses showed a high chemical element content, including C, O, S, Si, K, P, $\mathrm{Ca}, \mathrm{Na}, \mathrm{Cl}, \mathrm{Al}, \mathrm{Mg}, \mathrm{Fe}$, and Ti and we identified bacterial and fungal structures probably derived from the oronasal region [7]. The images of such elements can be easily distinguished from the ones of microorganisms - they correspond to inorganic structures with various elemental loads, of variable sizes $\left(60^{-1} \mu \mathrm{m}\right)$, some of which with slightly sharp or tortuous edges. The hazards for health of these identified inorganic and organic materials identified on masks and tubes from OSAS patients who use CPAP ventilation at home are multiple. Direct contact with the upper or lower airway structures, depending on the surface where they are located can lead to mechanical lesions of the soft tissue. Also, literature studies have shown that Zn and Ti surfaces may favor bacterial adhesion $[15,16]$ and thus increase the risk of infection.

The most frequently identified microorganisms were various types Staphylococcus and Candida colonies. These data confirm that the results of the SEM images are patent and pertinent. Piñar et al. [17] carried out a study including bot polymerase chain reaction and SEM and found a high fungal load on the Archimedes Palimpsest, particularly in degraded areas. We also identified many colonies with images compatible with the ones of fungi. Thus, the respiratoryairways of OSA patients are exposed to a double inorganic and organic risk, which in time can reduce patients' compliance with CPAP. The presence on the masks and tubes of microorganisms we identified is potentially linked to the non-replacement of CPAP materials according to norms [20]. According to The Lung Association Sleep Apnea Handbook [18] the replacement of mask, hose and headgear is recommended to be performed every 6 months. The study carried out in 2009 by Alex Horowit et al. [19] supports this recommendation, showing that after this time period microorganisms that adhere to their silicone surface can no longer be effectively removed regardless of frequency or methods of cleaning used. These surfaces may develop an optimal environment for sheltering oral or upper airway pathogens which, in time and in the absence of local disinfection means, favor complications and disorders of the upper and lower respiratory tract. We also observed that the presence of bacteria was more frequent in patients who used the devices for longer time periods, butthe lack of a statistically significant difference can be linked to the lack of use by our patients of optimal hygiene measures for the masks and tubes, regardless of the duration of use of the devices. Optimizing health education in this category of patients is an imperative requirement for the future. The presence of microorganisms on masks may be associated with a high incidence of airwaves infections. In a study conducted by Su et al. on a large group of patients, the authors demonstrate that pneumonia is much more frequent in patients with OSA [20].

Although there are methods for masks cleaning, from simple washing to complex cleaning systems consisting of activated oxygen-based devices [21], there are no inexpensive mask incorporated antimicrobial methods without associating procedures that may reduce patient compliance. This study provides additional elements allowing to extend the applicability of nanotechnology to sleep medicine. Such a solution would reduce costs associated with OSA treatment and reduce the health risks associated with the use of contaminated materials.

\section{Conclusions}

The use of the previously described complex methods allowed to demonstrate the presence of microbiological and inorganic structures on the surface of the masks and tubing of CPAP devices, which raises a flag on the risk of their inhalation into the upper and lower airways and on safety measures that need to be implemented to reduce this risk. Ourstudy opens new directions of research that can focus on the synthesis and incorporation in the mask and tubing structure of nanoparticles having an antibacterial, antifungal role, and an effect in reducing the adherence of inorganic particles to the mask and tubing surface.

\section{References}

1. SENARATNA, C. V., PERRET, J. L., LODGE, C. . ., LOWE, A. J., CAMPBELL, B. E, MATHESON, M. C, HAMILTON, G. S., DHARMAGE, S. C., Sleep. Med. Rev., 2016Jul 18, p. S1087

2. EPSTEIN, L. J., KRISTO, D., STROLLO, P. J., FRIEDMAN, N., MALHOTRA, A., PATIL S. P., RAMAR, K., ROGERS, R., SCHWAB, R. J., WEAVER, E. M., WEINSTEIN, M. D., Adult Obstructive Sleep Apnea Task Force of the American Academy of Sleep Medicine, J. Clin. Sleep. Med., 5, nr. 3, 2009, 263

3. TODEA, D. A. (coord.), [Sleep apnea and its comorbidities], Ed. Medicala Universitara Iuliu Hatieganu, Cluj Napoca, Romania, 2013.

4. VICTOR, L. D., Am. Fam. Physician., 69, nr. 3, 2004, p. 561

5. *** Comfort Classic Nasal CPAP Mask with Headgear. [last accessed 2017 March 1] Available at: http://www.cpap.com/ productpage/ comfortclassic-mask-headgear-respironics.html.

6. *** Foot Long $19 \mathrm{~mm}$ Diameter CPAP Hose with $22 \mathrm{~mm}$ Rubber. [last accessed 2017 March 1] Available at: $h$ ttp://www.cpap.com/productpage/ 6-tt-19-mm-cpap-hose-22-mm-rubber-ends.html.

7. COMAN, A. C., TODEA, D. A., POPA, F., RADU, T., CADAR, O., BORZAN, C., J. Optoelectron. Adv. M., 17, nr. 9-10, 2015, p. 1563

8. RODRIGUEZGONZALEZ-MORO, J. M., ANDRADE VIVERO, G., DE MIGUEL DÍEZ, J., LOPEZ MARTIN, S., SANCHEZ, C, IZQUIERDO ALONSO, J. L., DE LUCAS RAMOS, P., Arch. Bronconeumol., 40, nr. 9, 2004, p. 392

9. SANNER, B. M., FLUERENBROCK, N., KLEIBER-IMBECK, A., MUELLER, J. B., ZIDEK, W., Respiration., 68, nr. 5, 2001, p. 483

10.*** http://www.ingenlaboratory.ro/pdf/medii\%20de\%20cultura\% 20pentru\%20diagnostic\%20bacteriologic.pdf, [last accessed 2017 March $1]$.

11. ARMENTANO, I., ARCIOLA, C. R., FORTUNATI, E, FERRARI, D., MATTIOLI, S., AMOROSO, C. F., RIZZO, J., KENNY, J. M., IMBRIANI, M., VISAI, L., Sci. World. J., 2014, 2014, p. 410423

12. ZHOU, W., APKARIAN, R., WANG, Z. L., JOY, D., Fundamentals of Scanning Electron Microscopy (SEM), In: ZHOU, W., WANG, Z. L., Scanning Microscopy for Nanotechnology, Springer Science+Business Media, LLC, New York, USA, 1-40, 2007.

13. EFFREE, C. E., READ, N. D., Ambient- and low-temperature scanning electron microscopy, In: HALL, J. L., HAWES, C. R., Electron Microscopy of Plant Cells. Academic Press, London, UK, 1991.

14. KIERNAN, J. A., Microscopy Today, 8, nr. 1, 2000, p. 8

15. EGAWA, M., MIURA, T., KATO, T., SAITO, A., YOSHINARI, M., Dent. Mater. J., 32, nr. 1, 2013, p. 101

16. SHIDA, T., KOSEKI, H., YODA, I., HORIUCHI, H., SAKODA, H., OSAKI, M., Int. J. Nanomedicine., 8, 2013, p. 3955

17. PIÑAR, G, STERFLINGER, K., ETTENAUER, J, QUANDT, A., PINZARI, F, Microb. Ecol., 69, nr. 1, 2015, p. 118

18. *** Sleep Apnea Handbook [last accessed 2017 March 1] Available at https://www.ab.lung.ca/sitewyze/files/Sleep_Apnea_Handbook_2012.pdf. 19. HOROWITZ, A., HOROWITZ, S., CHUN, C., CPAP Masks are Sources of Microbial Contamination [last accessed on 2017 April 23] Available at: http://www.pureflowhealthcare.ca/pdf/Horowit__APSS_poster_2009_ mask_microbes.pdf

20. SU, V. Y., LIU, C. J., WANG, H. K., WU, L. A., CHANG, S. C., PERNG, D. W., SU, W. J., CHEN, Y. M., LIN, E. Y., CHEN, T. J., CHOU, K. T., CMAJ ., 186, nr. 6, 2014, p. 415

21. *** Sleep Diagnostics and Therapy [last accessed on 2017 March 1] Available at: http://www.carefusion.com/pdf/Respiratory/Sleep Diagnostics_and_Therapy/RC1145\% 20Diagnostic\%20 SoClean $\% 20$ Brochure.pdf.

Manuscript received: 9.12.2017 